\title{
Germany courts consensus not controversy
}

Munich. The future of basic research is probably safer in Germany than in any other European country. Pressure for greater emphasis on applied research is counterbalanced by such pillars of the basic research community as the Max Planck Society (which runs medium-sized research institutes), the large national research centres and the Deutsche Forschungsgemeinschaft (DFG, which funds university research in universities).

Indeed, these politically independent organizations successfully resisted the biggest post-war attack on basic research in Germany, which took place two years ago. This attack was prompted by the high costs of both re-equipping laboratories in the five new Länder and East Berlin, and assimilating them into the West German system, following reunification in 1990.

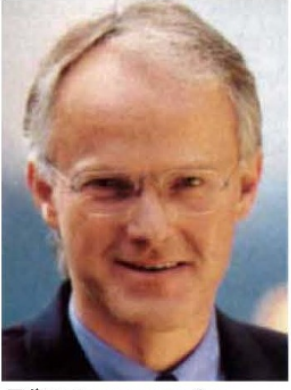

Rüttgers: wants advisory groups
These costs prompted a shift in the political debate on research at the end of 1992, away from issues directly concerning the East towards Germany's research system itself.

In particular, the government began listening to demands that public research should be more orientated to meeting industry's needs. Hans Zacher, president of the Max Planck Society, recalls 1993 as "a very bad experience". "It was as if Birnam wood had started to march on research, and in the wood were the combined troops of government and industry." Basic researchers had to justify their work at endless meetings convened by industrialists, he says, while the government considered devoting some national research centres to industry's service.

The political mood has shifted, however, and is now more reflective than aggressive. While the government recognizes that the transfer of technology from the country's strong science base to industry needs to be improved, the research ministry has toned down the more extreme demands of industry, summarized in the so-called Weule report (see Nature 372, 4; 1994).

The ministry of research has also rejected the idea that industry should have more direct control over the direction of state-funded research. In typical German fashion, the ministry has instead set about searching for the best means for research organizations, industry and government to reach a consensus on how to proceed.

For example, Paul Krüger, the former research minister, set up a 'strategy circle' of 14 scientists and industrialists to advise him on how technology transfer might be improved. He also set up a series of more focused 'dialogue circles' to identify areas of research that could directly benefit industry.

The ministry also convened regular meetings with the 'holy alliance', which includes the presidents of the Max Planck Society, the German Rektors conference, the AGF (the umbrella body of the national research centres), the Fraunhofer Society (which runs applied research institutes), the DFG and the Wissenschaftsrat - the German research council.

Last summer, the strategy circle recommended improving the legal environment for research - for example, by reducing the bureaucracy faced by biotechnology researchers - encouraging private support for research through tax incentives and developing special research programmes in state-funded laboratories in collaboration with industry. Discussions on strategy should also be continued at the ministry level, it added.

The German cabinet also approved plans last year to set up a high-level technology council made up of scientists, industrialists and representatives of the trade unions and ministries, and chaired by Chancellor Helmut Kohl. But this failed to take off at the time, because Kohl wanted to delay creating the council until after last October's general elections.

But the renewed appreciation of the importance of research and education to Germany's economy was emphasized again after the elections when the ministries of research and education were combined into a powerful "ministry for the future". Responsibility for the technology council was also transferred from the cabinet office to the new ministry; Jürgen Rüttgers, the new science minister, intends to hold its first meeting next month.

Rüttgers is also keen to establish what he terms a "German national academy of sciences" to supply independent advice on scientific issues. The plans have been controversial in the academic community, however, because the academy would include not only scientists but also representatives from industry, all political parties and trade unions.

In particular, the seven small local academies dotted around Germany feel particularly slighted - a real academy does not have this sort of composition, says Hubert Markl of the Berlin-Brandenburg Academy. The academies have written jointly to Rüttgers offering to provide the advisory service that he seeks.

The 'strategy circle' is also to be replaced by a holy alliance, which will be extended to include the presidents of the Humboldt Foundation and the Deutscher Akademischer Austausch Dienst. These organizations offer German fellowships and studentships to foreigners

How all these various advisory groups will work and interact with one another has not yet been outlined. But Rüttgers wants them to be up and running within the next few months.

Alison Abbott

\section{Science needs new role in new South Africa}

Cape Town. South Africa's research community will start the new year amid uncertainty about how much the government intends to spend on science and which areas will be supported.

Ben Ngubane, the minister for Arts, Culture, Science and Technology, will face a difficult task in persuading the cabinet to increase the R886-million (US\$252million) science budget in the face of other priorities.

Morale is low among scientists, and in particular basic researchers. The Foundation for Research Development (FRD), the government's agency for science and engineering research, will cease funding grant-holders at the end of the year, and invite them to apply for new programmes due for launch soon after.

These will include an 'open programme' for basic research, according to FRD, but the other programmes will be orientated towards industrial and social objectives: "competitive industry, improved quality of life, effective science, engineering and technology education and awareness," and "sustainable environment".

Olive Shisana, the special adviser to Nkosazana Dhlamini Zumathe, the health minister, also told deans of medical faculties, at a meeting last month, that medical research priorities should be directed towards improving access to health care. Most medical research is also funded from academic hospital budgets, but these are likely to be reduced in the next financial year, and the savings diverted towards primary and secondary health care

There is also concern that the R15 million that the Medical Research Council provides for university-based fundamental research may be under threat. "Even to contemplate eroding this minuscule amount is irresponsible," says Bob Millar, assistant dean (research) at the University of Cape Town Medical School. This money is particularly important in the training of medical researchers, he says, because it funds research in areas other than national health priorities.

Michael Cherry 